\title{
Efektifitas Sistem Jalan Underpass untuk Kota Pintar DKI Jakarta
}

\author{
Arman Syah Putra
}

Program Studi Sistem informasi, STMIK Insan Pembangunan, J1 Raya Bitung Banten e-mail: armansp@gmail.com

Submitted Date: August $31^{\text {st }}, 2020$

Revised Date: September $27^{\text {th }}$, 2020
Reviewed Date: September 22 $2^{\text {nd }}, 2020$

Accepted Date: September $30^{\text {th }}, 2020$

\begin{abstract}
This study discusses the effectiveness of the Underpass at the red light of Jalan Kramat Kebayoran Lama, South Jakarta, with the builder of the Underpass at the red light at Jalan Kramat Kebayoran, South Jakarta, DKI Jakarta. people come home from work, or in the morning and evening between 07:00 - 10:00 until 16:00 - 19:00, the method used is first by conducting a literature review or literature review study and second by conducting a field study, with doing a literature review then we will get problems from previous studies, with the review of literature can also add knowledge in the matter under study, then by field studies by looking directly at the place under study in order to retrieve accurate data. This underpass is very useful for residents to make it easy to cross to other areas without having to rotate far. In this research, we can find out the effectiveness of the Underpass at the red light of the old Jakarta Kebayoran Kramat Street, Jakarta. Underpas will change the activities of the surrounding community, for example by crossing the road will be further, and can find out what problems can be solved.
\end{abstract}

Keywords: Underpass; Red Light; Traffic; Solution

\section{Abstrak}

Penelitian ini membahas tentang efektifitas Underpass di lampu merah jalan kramat kebayoran lama Jakarta selatan, dengan pembangun Underpass di lampu merah jalan kramat kebayoran lama Jakarta selatan DKI Jakarta akan membantu memecahkan masalah yang ada seperti masalah kemacatan, kemacetan yang terjadi pada saat waktu masyarakat berangkat kerja dan masyarakat pulang kerja, atau pagi hari dan sore hari antara pukul jam 07:00 - 10:00 sampai jam 16:00 - 19:00, Metode yang digunakan adalah pertama dengan melakukan literature review atau studi tinjauan pustaka dan kedua melakukan studi lapangan, dengan melakukan tinjauan pustaka maka kita akan mendapatkan masalah dari penelitian sebelumnya, dengan tinjuan pustaka juga bisa menambah ilmu pengetahuan dalam hal yang diteliti, selanjutnya dengan studi lapangan dengan melihat langsung tempat yang diteliti agar bisa mengambil data yang akurat. Underpass ini sangat berguna bagi warga masyarakat untuk memudahkan menyeberang ke daerah lain tanpa harus memutar jauh. Pada penelitian ini bisa mengetahui efektifitas dari Underpass di lampu merah jalan kramat kebayoran lama Jakarta selatan DKI Jakarta, dengan dibuatnya Underpas akan merubah kegiatan dari masyarakat sekitar, misalkan dengan menyeberang jalannya akan lebih jauh, dan bisa mengetahui masalah masalah apa saja yang bisa diselesaikan.

Kata Kunci: Underpass; Lampu Merah; Macet; Solusi

\section{Pendahuluan}

Kemacetan adalah salah satu masalah yang banyak terjadi di semua kota besar dunia, bukan cuma Jakarta yang mengalami masalah tersebut, pimpinan kota Jakarta silih berganti dari gubernur ke gubernur lainnya tetapi masalah kemacetan belum bisa diselesaikan sampai detik ini juga, lalu siapa yang harus disalahkan dalam masalah ini
(Yang \& Wang, 2020), pemimpin yang tidak bisa bekerja atau masyarakatnya yang tidak bisa mengikuti aturan yang dibuat, sudah sepatutnya tidak saling menyalahkan dalam hal ini, malah harus saling bahu membahu dalam memecahkan masalah yang ada di kota Jakarta tercinta kita ini, dengan aturan yang jelas dan masyarakat menjalankan aturan tersebut dengan baik maka 
satu per satu masalah yang ada di kota kita tercinta Jakarta akan bisa terpecahkan (Putra, 2019).

Sistem yang sudah dibuat oleh pemerintah DKI Jakarta adalah dengan peraturan ganjil genap yang diterapakan di beberapa jalan ibu kota, namun apakah sistem ini berhasil dalam memecahkan masalah kemacetan, gubernur sebelumnya menciptakan peraturan 3in1, namun di bilang gagal karena bisa diakali oleh para pengendara bermotor roda empat, dengan peraturan yang ada maka harusnya bisa mengatasi masalah kemacetan yang ada, terutama di perempatan lampu merah yang sering terjadi kemacetan parah (Tjahjani \& Suharso, 2017).

Sumber kemacetan biasa terjadi di lampu merah atau perempatan yang dilalui empat jalur yang bertemu di satu jalur, dengan masalah tersebut maka pemerintah mencari solusi dalam permasalahan tersebut, solusi yang dibuat adalah membuat Underpass dan Flyover ( Enderzon, 2020), dengan ke dua jalur khusus tersebut maka akan bisa mengurangi kemacetan yang biasa terjadi.

Metode penelitian yang digunakan dalam penelitian ini adalah dengan menggunakan studi pustaka dan studi lapangan, dengan membaca banyak literature akan menambah wawasan akan penelitian yang diangkat dan mempelajari lapangan dengan melihat langsung kondisi tempat penelitian akan menambah pasti hasil penelitian yang diangkat (Novitasari, et al., 2020).

Pada penelitian ini diangkat masalah efektivitas dari Underpass yang berada di perempatan lampu merah jalan kramat kebayoran lama Jakarta selatan, dengan peneltian ini bisa mengetahui efektivitas pembuatan Underpass, diharapkan akan bisa dibuat contoh untuk pembanguan Underpass berikutnya di tempat lain.

\section{Landasan Teori}

Pada penelitian ini diangkat masalah tentang efektivitas Underpass jalan kramat kebayoran lama Jakarta selatan dan menghasilkan sebuah jawaban apakah Underpass jalan kramat kebayoran lama Jakarta selatan bisa memecahkan masalah yang terjadi selama ini (Fauzi, Suheryanto, \& Anwar, 2017), kemacetan memang menjadi masalah yang sulit ditemukan solusinya karena masyarakat Indonesia masih belum sadar akan ketertiban dalam berlalu lintas, dengan adanya Underpass jalan kramat kebayoran lama Jakarta selatan maka akan bisa membantu masalah kemacetan (Novitasari, et al., 2020).

\subsection{Lampu Merah}

Lampu merah adalah menurut UU no. 22/2009 tentang Lalu lintas dan Angkutan Jalan dengan sebutan alat pemberi isyarat lalu lintas atau APILL (Risnadinata, Kumara, \& Ariastina, 2020), dengan adanya lampu merah akan bisa mengatur jalannya lalu lintas di suatu jalan, namun dengan kondisi sekarang ini lampu merah menjadi tempat kemacetan terjadi, dan bahkan bisa macet panjang jika di jam sibuk di pagi dan sore hari, pemerintah membuat Flyover dan Underpass di beberapa lampu merah untuk mengatasi kemacetan di lampu merah, adapun gambar lampu merah bisa dilihat di bawah ini:

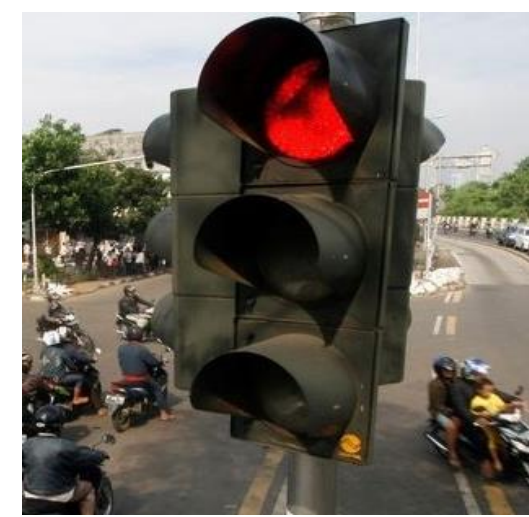

Gambar 1 lampu merah Sumber:

https://www.reqnews.com/news/5293/29-lampumerah-belum-beroperasi-terimbas-pamadamanlistrik-massal

\subsection{Kebijakan Publik Tentang Mengatasi Masalah Kemacetan}

Suatu kebijakan publik dibuat untuk membantu menyelesaikan masalah yang ada di suatu daerah, pada peneltian ini kebijakan publik di bidang transportasi untuk mengatasi kemacetan yang biasa terjadi di lampu merah, ada beberapa kebijakan di buat untuk mengatasi hal tersebut namun ada yang berhasil dan ada yang kurang tepat, adapun kebijakan publik untuk mengatasi kemacetan adalah sebagai berikut (Novitasari, et al., 2020):

\section{a. 3in1}

3in1 artinya adalah tiga orang dalam satu mobil, dengan tiga orang diharapkan akan bisa mengurangi jumlah kendaraan mobil di jalur sibuk dan penting seperti jalan Jendral Sudirman dan jalan MH Thamrin, Sistem 3 in 1 ini dibuat berdasarkan Keputusan Gubernur Daerah Khusus Ibukota Jakarta, No. 4104/2003 tertanggal 23 Desember 2003. DKI Jakarta waktu itu di pimpin 
oleh Gubernur Sutiyoso, Gubernur Sutiyoso sengaja membatasi mobil pribadi lewat kawasan tertentu terutama jalan Jendral Sudirman dan Jalan MH Thamrin, karena termasuk jalan Protokol dan sering di lewati para pejabat dan pimpinan negara, jadi diharapkan tidak macet pada saat diperlukan, di bawah ini adalah foto kecurangan yang dilakukan para pengendara agar berpenumpang tiga orang dan bisa melewati jalur 3in1 dengan menyewa joki di pinggir jalan.

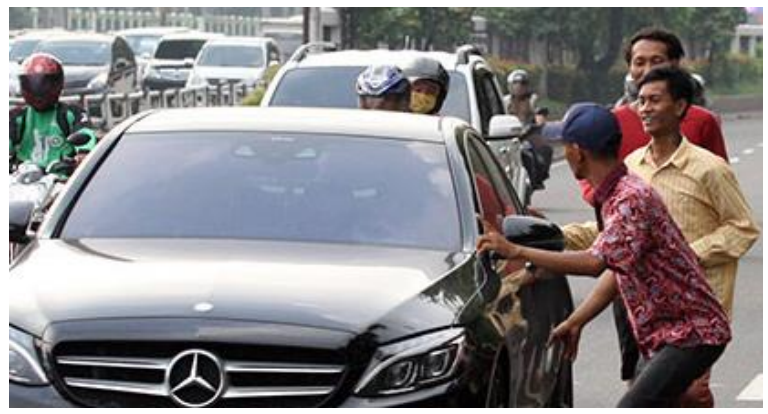

Gambar 2 Mobil menggunakan jasa joki 3in1

Sumber:

https://mediaindonesia.com/read/detail/38448mengaku-tidak-tahu-pengemudi-ini-tetap-sewajoki-3-in-1

\section{b. Ganjil dan Genap}

Pada saat gubernur DKI Jakarta bapak Basuki Cahya Purnama alias Ahok peraturan ganjil genap di sahkan dengan menerbitkan peraturan Gubernur Provinsi Daerah Khusus Ibukota Jakarta Nomor 164 Tahun 2016 tentang pembatasan lalu lintas dengan sistem ganjil genap, di dalam peraturan tersebut di tuang kan kawasan penerapan ganjil genap hingga sanksi yang diberikan kepada pelanggar peraturan ganjil genap. sistem ganjil genap adalah suatu kendaraan bisa melewati jalur yang telah ditentukan jika memiliki plat sama dengan sistemnya, jika pelat nomor kendaraan genap maka bisa melewati jalur tersebut pada tanggal genap saja, begitu pula dengan sistem ganjil, sistem ganjil genap masih digunakan sampai dengan sekarang ini agar bisa mengurangi volume kendaraan di suatu jalan yang sering terjadi kemacetan, di bawah ini adalah foto dari papan pengumuman peraturan ganjil genap (Putra, et al., 2020).

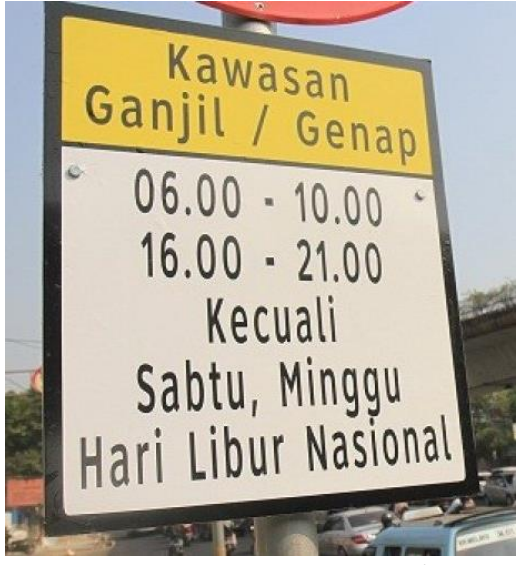

Gambar 3 Papan Pengumuman Sistem Ganjil Genap

Sumber:

https://www.suara.com/news/2020/01/03/080931/ awas-sistem-ganjil-genap-di-jakarta-kembaliberlaku-hari-ini

\section{c. Flyover}

Flyover pertama di Indonesia terdapat di Jakarta dibangun dari cawang ke tanjung priuk tahun 1987 oleh perusahaan yang bernama PT Hutama Karya, Flyover ini dibangun untuk mempermudah jalur dari cawang langsung ke tanjung priuk tanpa harus mengalami hambatan kemacetan dan mempersingkat waktu, di bawah ini adalah foto salah satu Flyover yang terdapat di Jakarta (Tjahjani \& Suharso, 2017).

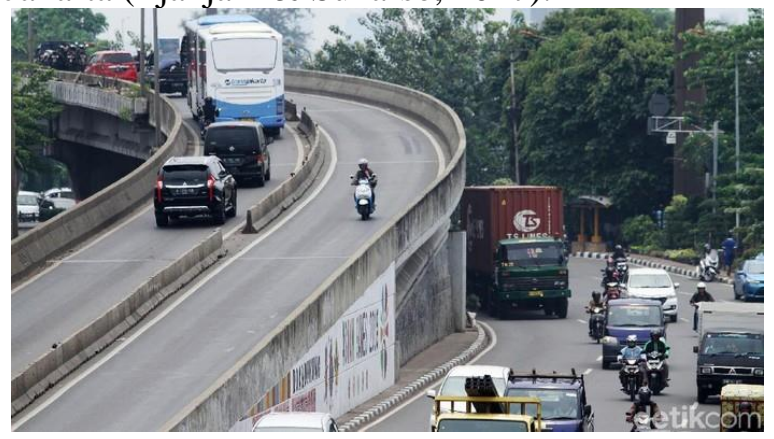

Gambar 4 flayover di Jakarta

Sumber: https://news.detik.com/berita/d4665679/pemprov-dki-bangun-3-flyover-baru-di2020

\section{d. Underpass}

Underpass pertama di Jakarta adalah Underpass kemayoran, yang sebelumnya adalah landasan lapangan udara kemayoran (Wibawa, Redana, Suthanaya, \& Wiryasa, 2020), Underpass kemayoranmenghubungkan dua daerah yang tadinya terputus dikarenakan adanya landasan udara kemayoran, namun Underpass kemayoran sering terjadi banjir jika hujan turun dan jika air 
laut sedang pasang, harus didesain ulang Underpass kemayoran jika ingin berfungsi maksimal, adapun di bawah ini foto dari Underpass di wilayah lampung (Tjahjani \& Suharso, 2017).

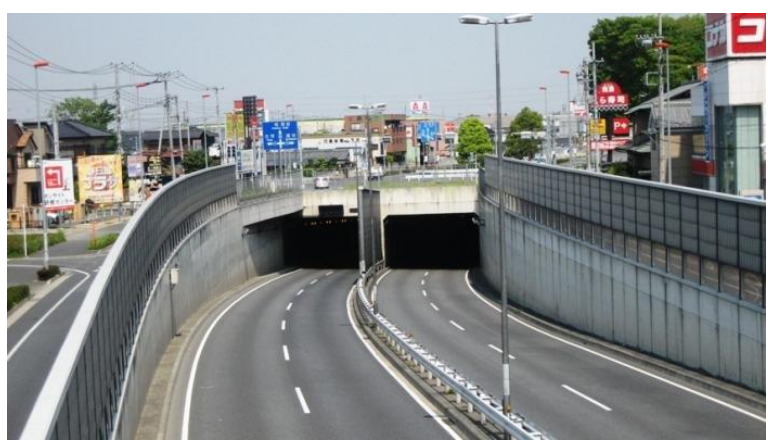

Gambar 5 Underpass di Lampung

Sumber :

http://m.harianmomentum.com/read/7401/des ain-konstruksi-underpass-unila-berubah

\subsection{Lokasi Penelitian}

Di bawah ini adalah hasil foto dari studi lapangan untuk mengetahui keadaan lokasi penelitian, adapun beberapa foto yang diambil, bisa di lihat di bawah ini:

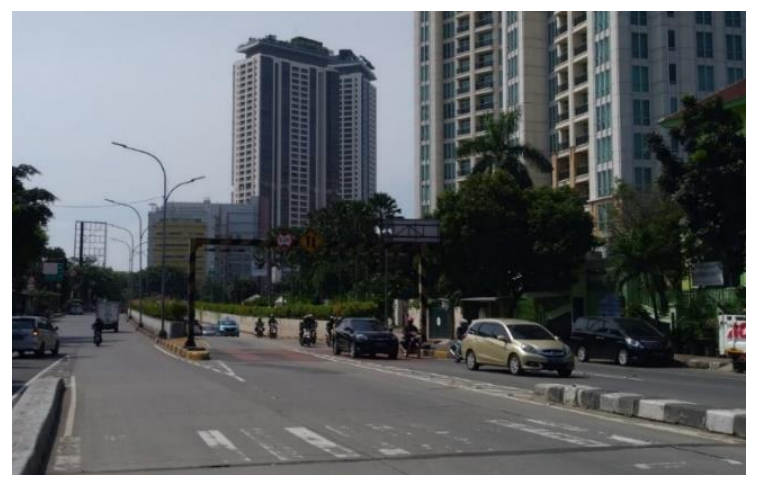

Gambar 6 Underpass Jalan Kramat Kebayoran

Lama Jakarta Selatan

Gambar 6 adalah gambar Underpass jalan kramat kebayoran lama Jakarta selatan yang diangkat dalam peneltian ini, gambar di atas adalah gambar dari studi lapangan yang melihat langsung kondisi di lapangan, gambar di atas diambil jam 11:00 WIB, Underpass jalan kramat kebayoran lama Jakarta selatan sering terjadi kemacetan di pagi hari dan sore hari, kemacetan di pagi hari di mulai jam 07:00 WIB sampai jam 10:00, dan kemacetan di sore hari mulai jam 16:00 sampai jam 19:00, dikarenakan jam pulang kerja, jadi kemacetan hanya di waktu waktu tertentu saja.

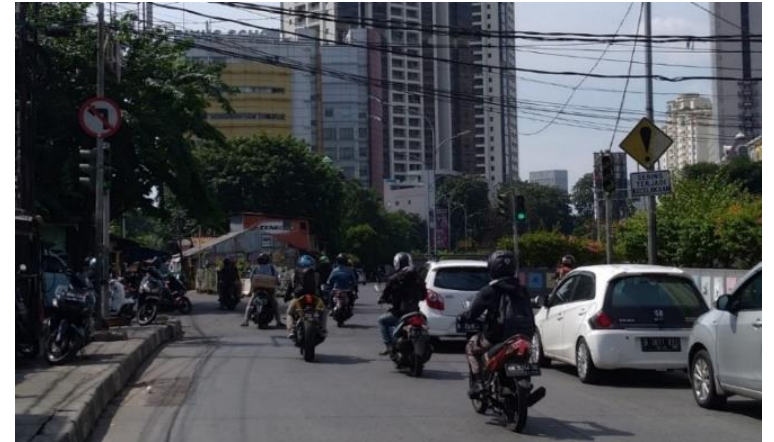

Gambar 7 Lampu Merah Jalan Kramat

Kebayoran Lama Dari Arah Teuku Nyak Arief Ke Arah Permata Hijau

Gambar 7 adalah gambar lampu merah jalan Kramat Kebayoran Lama dari arah jalan Teuku Nyak Arief ke arah permata hijau, dengan dibangunnya Underpass Jl. Kramat Kebayoran Lama Jakarta Selatan membuat lampu merah di atasnya berkurang volume kendaraannya, dengan kata lain berkurang tingkat kemacetannya karena kendaraan yang mau ke arah permata hijau bisa melewati Underpass tanpa harus melewati lampu merah, jadi tanpa memberhentikan kendaraan.

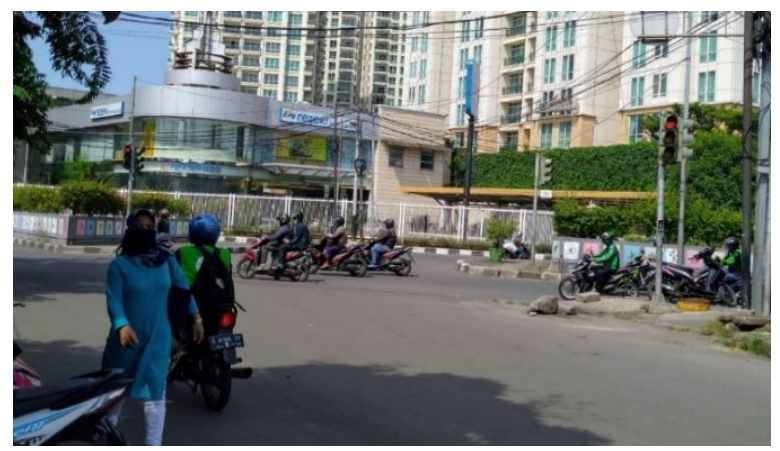

Gambar 8 Lampu Merah Jalan Kramat

Kebayoran Lama Dari Arah Jalan Kramat Ke Arah Jalan Ophir

Gambar 8 adalah gambar lampu merah jalan Kramat kebayoran baru ke arah jalan Ophir, lampu merah ini sering terjadi kemacetan karena sebelum lampu merah ini ada pasar bata putih kebayoran lama, dengan berdekatannya lokasi maka menambah kemacetan yang terjadi di waktu pagi dan sore hari, dengan dibangunnya Underpass maka banyak membantu mengurangi kemacetan yang ada di lampu merah jalan Kramat Kebayoran Baru Jakarta Selatan. 


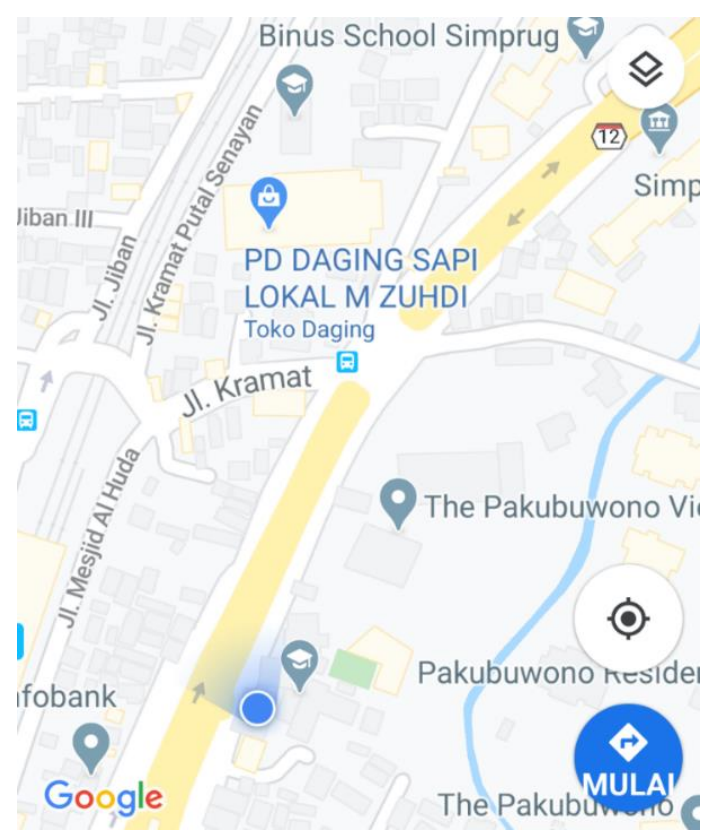

Gambar 9 Lampu Merah J1. Kramat Kebayoran

Lama Jakarta Selatan dengan menggunakan aplikasi goole map

Gambar 9 adalah gambar Underpass jalan kramat kebayoran lama Jakarta selatan yang diambil menggunakan aplikasi Google Map dengan View biasa atau normal, karena letaknya yang strategis maka pemerintah perlu membangun Underpass di perempatan lampu merah jalan kramat kebayoran lama Jakarta selatan.

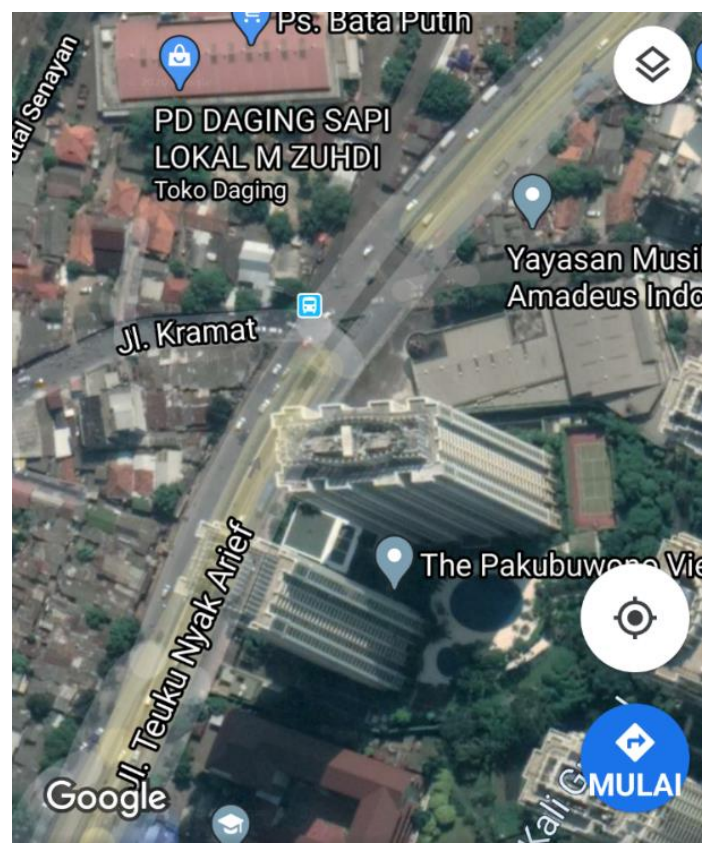

Gambar 10 Lampu Merah Jl. Kramat Kebayoran Lama Jakarta selatan menggunakan aplikasi google map
Gambar 10 adalah gambar Underpass jalan kramat kebayoran lama Jakarta selatan yang diambil menggunkan aplikasi google map dengan view real map atau kondisi asli di lapangan, dengan melihat gambar yang asli sesuai dengan lapangan maka peneliti bisa melihat kondisi lapangan dan bisa menilai kondisi lapangan yang sesungguhnya.

\section{Metodologi}

Metode yang digunakan adalah dengan studi pustaka dan studi lapangan, dengan kedua metode tersebut maka akan diharapkan akan menghasilkan penelitian yang bisa memaksimalkan hasilnya, dengan menggunakan metode ini peneltian ini akan menghasilkan sebuah jawaban dalam penggunaan Underpass di jalan kramat kebayorn lama Jakarta selatan, adapun gambar metode penelitian bisa dilihat pada Gambar 11 .

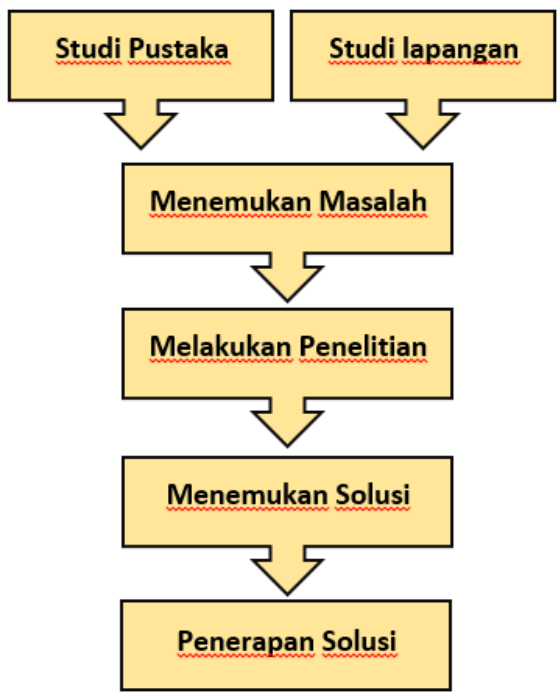

Gambar 11 Metode Penelitian

Penjelasan tahapan metode penelitian pada Gambar 11 adalah sebagai berikut:

a. Studi Pustaka

Tahapan ke 1 dalam penelitian ini adalah melakukan studi pustaka dengan membaca buku dan jurnal di perpustakaan. Dengan membaca akan bisa membantu penelitian ini dalam hal wawasan yang bisa diambil dari penelitian sebelumnya, juga bisa menambah wawasan dalam hal penelitian yang diangkat.

b. Studi Lapangan

Tahapan ke 2 dalam penelitian ini adalah dengan melakukan studi lapangan dengan cara melakukan survei lokasi 
penelitian, dengan melihat langsung dan mengamati tempat penelitian akan bisa memperoleh data yang real atau nyata, karena diambil langsung di lokasi penelitian, data yang real akan bisa menjawab dari masalah yang diangkat.

c. Menemukan Masalah

Tahapan ke 3 dalam penelitian ini adalah dengan menemukan masalah dari hasil melakukan tahapan ke 1 dan ke 2, dengan melakukan studi pustaka dan studi lapangan maka akan mengahasilkan masalah yang bisa diangkat dalam penelitian ini, dengan melakukan tahapan ke 1 dan ke 2 maka akan menemukan masalah yang terbaru dan belum pernah diteliti.

d. Melakukan Penelitian

Setelah tahapan ke 3 selesai dan peneliti menemukan masalah yang terbaru, maka penelitian bisa dilakukan ke tahap selanjutnya, dengan melakukan peneltian itu sendiri, penelitian akan maksimal jika sudah memiliki konsep penelitian, jadi penelitian tersebut tidak bias dan kemana mana, jadi fokus ke satu masalah penelitian yang diangkat saja.

e. Menemukan Solusi

Setelah semua tahapan dilewati maka penelitian akan berakhir dan solusi dari masalah yang diteliti sudah ditemukan, dengan selesainya penelitian maka akan menambah pengetahuan baru dalam hal yang diteliti.

f. Penerapan Solusi

Tahapan terakhir dalam penelitian ini adalah dengan penerapan solusi, hasil dari penelitian ini adalah dengan mengetahui bahan penelitian yang di angkat mempunyai fungsi yang berguna untuk masyarakat luas, dan bisa menjadi bahan referensi untuk solusi kemacetan ke depannya.

Dari ke 6 tahapan metode penelitian di atas maka selesai sudah penelitian ini, dengan menggunakan metode penelitian maka peneltian akan mempunyai alur yang bisa dijadikan landasan untuk dasar sebuah penelitian.

\section{Hasil Dan Pembahasan}

Pada penelitian ini dilakukan survei kepada 100 orang masyarakat yang ada di sekitar Underpass lampu merah jalan kramat kebayoran lama Jakarta selatan dan melakukan wawancara kepada pengguna jalan yang melewati Underpass lampu merah jalan kramat kebayoran lama Jakarta selatan, dengan melakukan kedua hal tersebut maka telah dilakukan studi lapangan agar bisa mendapatkan data yang valid untuk menemukan pemecahan masalah yang diangkat pada penelitian ini, adapun hasil survei dan wawancara bisa dilihat pada subbab berikutnya.

\subsection{Survei}

Di bawah ini adalah hasil survei kepada 100 orang masyarakat yang tinggal di daerah sekitar Underpass lampu merah jalan kramat kebayoran lama Jakarta selatan, dengan rentang usia 20-30, usia 31-40, usia 41-50, usia 51-60. Kenapa dipilih usia tersebut, dikarenakan usia tersebut adalah usia yang masih produktif yang masih melakukan mobilitas keseharian melewati Underpass atau lampu merah jalan kramat kebayoran lama, adapun hasil survei tersebut dibuat sebuah diagram agar pembaca bisa mengerti jika melihatnya, gambarnya bisa dilihat di bawah ini:

\section{SURVEY KEPADA 100 ORANG MASYARAKAT BERDASARKAN USIA DI SEKITAR UNDERPASS JALAN KRAMAT KEBAYORAN LAMA}

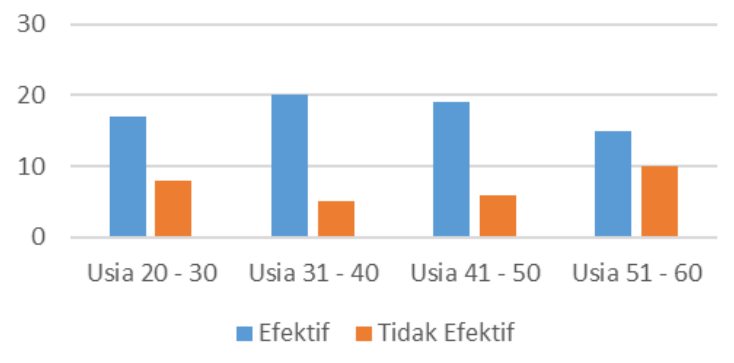

Gambar 12 Diagram Hasil Surve Terhadap 100 Orang Masyarakat Sekitar Underpass

Gambar di atas adalah gambar diagram hasil survei yang dilakukan untuk mengetahui efektivitas dari Underpass lampu merah jalan kramat kebayoran lama Jakarta selatan, dari hasil survei menunjukkan bahwa Underpass lampu merah jalan kramat kebayoran lama Jakarta selatan sangat efektif dan sangat membantu mengurangi kemacetan yang sering terjadi sebelum dibangun Underpass lampu merah jalan kramat kebayoran lama Jakarta selatan, jadi hasil penelitian ini bisa dijawab adalah sangat efektif Underpass lampu merah jalan kramat kebayoran lama Jakarta selatan.

\subsection{Hasil Wawancara}

Berikut ini adalah hasil wawancara dari masyarakat sekitar Underpass lampu merah jalan 
kramat kebayoran lama Jakarta selatan. Dengan melakukan wawancara maka akan bisa mengetahui permasalahan yang terjadi di lapangan dan bisa mengetahui jawaban dari masalah penelitian yang diangkat, adapun hasil wawancara bisa di lihat di bawah ini:

a. Budi, 35 Tahun, Pedagang: semenjak ada Underpass lampu merah jalan kramat kebayoran lama Jakarta selatan ini, kemacetan sedikit berkurang dan jalur ke permata hijau jauh lebih lancar.

b. Sari, 25 Tahun, Marketing Staff: kemacetan di lampu merah jalan kramat memang terjadi setiap hari maka saya setuju dan sangat mendukung telah dibangunnya Underpass lampu merah jalan kramat kebayoran lama Jakarta selatan, karena bisa mengurangi kemacetan.

c. Jamal, 50 Tahun, Tukang Ojek Pangkalan: meski kemacetan berkurang namun penyebrang jalan agak susah untuk menyebrang jalan, harus ke lampu merah terlebih dahulu.

d. Sila, 45 Tahun, Pedagang: meski Underpass berguna banyak untuk masyarakat sekitar namun untuk penyebrang jalan agak sedikit muter jauh untuk menyebrang jalan.

e. Khalif, 21 Tahun, Mahasiswa: sangat membantu untuk mengatasi kemacetan yang ada dan bisa mengurangi volume kendaraan di lampu merah.

\subsection{Kelebihan dan Kekurangan Underpass}

Dalam sebuah sistem atau pembuatan suatu proyek ada kelebihan dan kekurangan karena semua sistem tidak ada yang sempurna, adapun kelebihan dan kekurangannya bisa dilihat di bawah ini:

a. Kelebihan

- Mengurangi kemacetan

- Pengalihan volume kendaran

- Mengurangi tingkat kecelakaan

b. Kekurangan

- Menggunakan lahan yang luas

- Membuat penyebrang jalan harus memutar sedikit jauh

- Kecepatan pengendara tinggi

Dari studi lapangan yang dilakukan maka didapatkan hasil dari permasalahan yang diangkat dari penelitian ini adalah mayoritas masyarakat menilai kemacetan berkurang dengan adanya
Underpass jalan kramat kebayoran lama Jakarta selatan.

\section{Kesimpulan}

Pada penelitian ini diangkat masalah efektivitas Underpass lampu merah jalan kramat kebayoran lama Jakarta selatan, dengan selesainya tahapan dalam metode penelitian maka selesai sudah penelitian dan sudah bisa menemukan jawaban dari pertanyaan yang menjadi masalah yang diangkat pada penelitian ini, adapun kesimpulan pada penelitian ini bisa dilihat di bawah ini

a. Efektivitas Underpass lampu merah jalan kramat kebayoran lama Jakarta selatan sangat membantu dalam memecahkan masalah di lampu merah jalan kramat Jakarta selatan, dengan adanya Underpass lampu merah jalan kramat kebayoran lama Jakarta selatan kemacetan berkurang pada jam sibuk masyarakat berangkat bekerja dan pulang bekerja, jadi sistem Underpass bisa diterapkan di jalan ibu kota lainnya yang sering terjadi kemacetan dan ingin menguranginya.

b. Penelitian kedepannya bisa dengan membuat sistem Underpass yang bisa membantu dalam mengatasi kemacetan bukan hanya di perempatan lampu merah saja, tapi bisa digunakan Underpass di jalan lurus dan jumlah pertambahan jalan bertambah.

\section{Daftar Pustaka}

Enderzon, V. Y. (2020). Identifikasi Risiko Proyek Konstruksi Flyover dan Underpass di Indonesia (Kajian Literatur). Rekayasa Sipil / Volume 14, No.2 - 2020 ISSN 1978 - 5658, 104-111.

Fauzi, H. W., Suheryanto, \& Anwar, S. (2017). Analisis Pengembangan Jalan Tidak Sebidang (Underpass) di Jalan Jenderal Sudirman Jalan Sultan Agung Kabupaten Brebes. Jurnal Konstruksi, Vol. VI, No. 3, Januari 2017, 255268

Novitasari, D., Masduki , A., AGUS , P., Joni , I., Didi , S., Nelson, S., \& Arman, S. P. (2020). Peran Social Support terhadap Work Conflict, Kepuasan dan Kinerja. JPIM (JURNAL PENELITIAN ILMU MANAJEMEN), 187202.

Putra, A. S. (2019). "Smart City : konsep Kota pintar di DKI Jakarta". Jurnal TEKINFO, Vol 20, No 2, Hal 1-111, ISSN 1411-3635.

Putra, A. S., Novitasari, D., Asbari, M., Purwanto, A., Iskandar, J., Hutagalung, D., \& Suroso. (2020). "Examine Relationship of Soft Skills, 
Hard Skills, Innovation and Performance: the Mediation Effect of Organizational Le. IJSMS. Risnadinata, P., Kumara, I., \& Ariastina, W. (2020). Management of Flood Protection System of Dewa Ruci Underpass in Bali. Journal of Electrical, Electronics and Informatics, Vol. 4 No. 2, August 2020, 57-63.

Tjahjani, A. I., \& Suharso. (2017). Kajian Masa Konstruksi Rekayasa Lalu Lintas. Prosiding Simposium Forum Studi Transportasi antar Perguruan Tinggi ke-20 Universitas Hasanuddin, Makassar, 4 - 5 November 2017, 663-670.
Wibawa, I. S., Redana, I., Suthanaya, P. A., \& Wiryasa, N. A. (2020). Understanding Vertical Holiness as a Received Business on Underpass Development. International Journal of Engineering and Emerging Technology, Vol. 5, No. 1, January-June 2020, 50-56.

Yang, Z., \& Wang, X. (2020). Influence of Metro Tunnel Excavation on Deformation of Existing Pedestrian Underpass in Changzhou Railway Station Platform. ACCESS.2020.2981343, 55860-55871. 